\title{
Back at the kitchen table: Reflections on decolonising and internationalising with the Global South socio-legal writing workshops
}

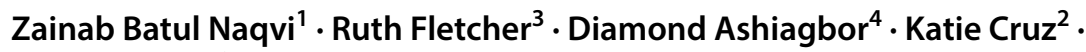 \\ Yvette Russell ${ }^{2}$
}

Published online: 1 August 2019

○) Springer Nature B.V. 2019

\begin{abstract}
It has been three years since we held the Feminism, Legality and Knowledge (FLaK) seminar to respond to our developing frustrations and excitement around feminist legal studies and academic publishing. In the wake of our 25th anniversary in 2018 , we critically reflect further on our original intention to stock up on decolonising techniques to mix feminism, legality and knowledge whilst building on previous consideration of our self-proclaimed 'international' status. These reflections are prompted by editorial board members' experiences as participants in the Cardiff Law and Global Justice Centre's British Academy-funded Global South SocioLegal Writing Workshops in Accra (Ghana), Nairobi (Kenya) and Recife (Brazil) in 2018. Following an explanation of the concerns with academic publishing that have prompted this reflection, we provide a narrative of our experiences in each of the three workshops exploring the lessons learned and their impact on our practice as editors and scholars in feminist legal studies. We finish with a renewal of our commitment to decolonise our minds and practices by continuing to struggle to earn the label 'international' for the journal now and in future. A brief introduction to the contents of this issue of FLS follows the reflection.
\end{abstract}

Zainab Batul Naqvi

zainab.naqvi@coventry.ac.uk

1 Coventry University, Coventry, UK

2 University of Bristol, Bristol, UK

3 Queen Mary University of London, London, UK

4 University of Kent, Canterbury, UK 


\section{Introduction: on FLaK and the Global South in academic publishing}

The call for rediscovery and the resumption of our language is a call for a regenerative reconnection with the millions of revolutionary tongues in Africa and the world over demanding liberation. It is a call for the rediscovery of the real language of humankind: the language of struggle. It is the universal language underlying all speech and words of our history. Struggle. Struggle makes history. Struggle makes us. In struggle is our history, our language and our being. (Ngũgĩ wa Thiong'o 1986, 108)

It is time to move beyond the Marx who found it possible to say: They cannot represent themselves; they must be represented. (Chandra Talpade Mohanty 1984, 354)

It is essential for us to remember that interdisciplinary movements around critical and socio-legal studies were fashioned and shaped by universities in the Global South (Harrington and Manji 2017a, 703). Law schools in Dar es Salaam, Port Moresby and New Delhi provided the appropriate environment for these areas of study to flourish (Harrington and Manji 2019). Feminist legal studies then, has a debt to the pioneering, ground-breaking work and scholars coming out of these institutions. And yet, recent research has shown that this is barely recognised today, which is why we have started to ask ourselves some important questions (Briggs and Weathers 2016; Harrington and Manji 2017a; Medie and Kang 2018).

Questions such as: What is the mark of a successful researcher in academia? How do we define good scholarship? These initial questions underpin our exploration of FLS' interactions with the Global South and our understanding of the issues that we urgently need to highlight and address. Carli Coetzee notes that the published article and monograph are the preferred currencies of academia (2018). They determine the trajectory of our careers and development opportunities. Articles and books with our name on evidence the ability to conduct rigorous, impactful and engaging research that contributes to knowledge and is therefore good scholarship. Published outputs may then be subjected to some form of quality rating system which impact on institutional and individual reputation and funding. The focus here is more on the result, output or deliverable rather than on the process that leads to publication.

As editors who are part of this process of exchange in academic currency, we want to investigate our role in peer review and its impact. Double-blind peer review may be the ultimate indicator of research quality to the industry (and yes, it is an industry) in which we are operating, but this is largely invisible: hidden behind a smokescreen with mystery authors and mystery reviewers who are kept from knowing one another's identities. As an editorial board, our visibility constantly shifts and changes according to the situation and circumstances. Our names are publicly listed on the journal website and on print copies but the 'free labour' we perform individually and collectively is largely carried out behind closed doors. Coetzee terms this an example of the occult economy whereby wealth is generated by an endeavour or enterprise without visible labour being performed $(2018,104)$. The academic journal is thus shrouded in secrecy and a sense of mystique for authors submitting their 
work. This shadowy approach 'fuels rumours and mistrust about which authors are valued and get to "add value" (Coetzee 2018, 104) by being selected to publish their work in the journal. Without critical and reflexive processes, we risk affirming a poorly regulated market with its power-laden messages about what counts as valuable scholarship and worthy researchers. Worryingly, this has an effect on research and knowledge around the globe.

As a journal that circulates mostly in the Global North we must address the effects of our publication process. This circulation is messy especially given the porosity between the borders of North and South (Mohanty 2002, 505) but overall Global North knowledge is given more prominence. As Manji and Mandler have shown (2019), the direct and indirect modes of making research happen raise significant political questions about how knowledge production and knowledge producers are valued. It is unsurprising that the publishing economy has a disproportionately negative impact on the perceived value of research and researchers in the Global South. The academic publishing industry in the Global North is still informed by colonialist, civilising mission judgements of knowledge and knowledge production. More broadly, Global South scholars' struggles are shaped by the Global North's 'neglect of historical and contemporary global factors such as colonialism and neoliberalism' (Medie and Kang 2018, 38). These factors have caused the 'skewed allocation of resources, authority and prestige in the international academic scene' leading to scholars being characterised as 'junior partners' or 'native informants' (Harrington and Manji 2019). This attitude manifests the Empire's haughty attitudes of superiority towards the colonies and their knowledge. As Wanelisa Xaba aptly summarises: 'in the colonial imagination, people of colour have never produced knowledge' (2018, 72). Global South research and scholars are being marginalised because their knowledge and scholarship is simply not being recognised and supported like that of their counterparts in the Global North. Moreover, the issue is one of forced translation. Publications in the Global North publish work that is written in their disciplinary and intellectual language. Room for deviation from this is limited and fails to account for the historical pillaging and silencing of Global South languages, knowledge, communication and ways of being. Liberation from colonisation is partly achieved by the recognition of diverse ways of producing, recording and sharing knowledge; to acknowledge that which was ripped away from people and provide the space and time for it to be rediscovered and regenerated. This speaks to Ngũgĩ wa Thiong'o's call for the rediscovery of humankind's universal language as a way of decolonising the mind. The universal language of struggle to be seen, to be heard and to be valued in history and the present day (1986, 108; see also Lebeloane 2017).

One example of this 'lost in translation' effect is that Africa-based authors are less likely to generalise and focus their discussions on a specific number of countries in Africa (Briggs and Weathers 2016). The opposite is true of those authors based outside of Africa who do generalise: their findings 'pertain' to the whole African continent. This demonstrates how the careful and more precise characteristics of some scholarship produced by some Africa-based authors affects the perception of their research as limited in scope and therefore less relevant for an international or Global North publication. In being cautious, their research gets lost in translation 
and is given less prominence because it lacks the same levels of generalisation. This exemplifies Valverde's argument that an assumption exists whereby 'the more of the world one's account claims to encompass, the more prestige one has as an intellectual' (Valverde 2015; Fletcher 2015b, 246).

These issues require urgent attention. We must challenge the erroneous assumption being perpetuated that it is desirable for the Global North to authoritatively speak for and write about the Global South. Without better representation of the Global South and its researchers, the risk of being subjected to the orientalist Global North gaze and watched through the lens of those who do not have appropriately situated expertise or legal know-how, is strengthened. Thus, it is important for advancing understanding and knowledge overall to have Global South voices and scholarship represented in publications. There is so much that the Global North academic scene needs to learn, including how to support and champion the fact that Global South experts and ideas matter (Briggs and Weathers 2016; Medie and Kang 2018).

This leads us back to our FLaK kitchen table where we think more deeply about how we mix feminism, legality and knowledge. At our kitchen table, we consider how FLS may best use 'its food, equipment, techniques, times, spaces, mood energy and commitment' (Fletcher 2015b, 214) as we reflect on our own participation in academic publishing and the conditions of research production. Here, we take a step back from the table to think about what is on it because we need to ask ourselves: what are we mixing? More specifically, what knowledge are we mixing? And how? If it fails to sufficiently include Global South knowledge, then what does that mean for us as a journal and field of enquiry?

One of the key ways of mixing FLaK involves stocking up on decolonising techniques (Fletcher 2015b) and by engaging more with these, we can start to look for answers. A mixture of emotional and financial investments are scattered across our kitchen table and we need to negotiate these whilst tackling our questions. Decolonising techniques involve giving spaces and opportunities to the silenced, marginalised and dismissed to be seen, heard and most importantly felt 'on their own terms' (Lugones 2010). Our emotions and our free labour are invested in this work, but this can compete with other emotional and financial constraints. One of the biggest financial limitations is the publishing charges we have limited control over and dictate who can access the knowledge published in FLS. This work is also emotionally taxing. Battling the hegemony, the 'monolith of modernity' (Kotiswaran 2015) and the established status quo drains and leaves us with fewer emotional resources, but more determined than ever to employ decolonising techniques. Additionally, we must be mindful of reining in our emotional investments as a board who are in the Global North. Part of our job is to make more space at the table and even get up from it if the occasion calls to stop ourselves from taking seats that belong to colleagues in the Global South. It is through this that we become more international (Fletcher et al. 2016).

We now reflect on our experiences at the Socio-Legal Global South Writing Workshops to think through how our Global North position affects our mixture of feminism, legality and knowledge and leads to our shortcomings in decolonising and internationalising. 


\title{
On the Global South writing workshops: Accra, Recife and Nairobi
}

\section{ACCRA: Professor Diamond Ashiagbor}

\author{
'Yes. Work is love made visible.' (Ama Ata Aidoo 1977)
}

Before colonisation, the Ga people of Ghana settled in Accra, creating a base for trade with the Portuguese who had a fortress on the coast nearby. In 1877, the colonial capital of Ghana was moved by the British to Accra which then remained an important trade location throughout colonial rule. Ghana was later the first subSaharan African colony to gain independence from British rule in 1957. As a trailblazer for independence then, we could not have thought of a better location to kickstart this round of writing workshops.

The Accra workshop was coordinated in partnership with the Ghana Institute of Advanced Legal Studies (GIALS) in particular, interim GIALS director, Victor Chimbwanda, and led by editors from the Journal of Law and Society (John Harrington, Cardiff), Modern Law Review (David Kershaw, LSE), and Feminist Legal Studies (Diamond Ashiagbor, Kent). A total of eleven African doctoral and postdoctoral scholars from Ghana, Kenya, Nigeria and Zimbabwe-based in these countries and also in South Africa-participated in the workshop.

The workshop began with an exploration of the ongoing process of decolonisation and its relationship to the history of legal scholarship on the continent of Africa - in particular, the importance of recognising the critical and socio-legal heritage of post-independence law schools. As Ambreena Manji and John Harrington have documented (2017b), the 'law in context' approach which emerged in the post-colonial era owed much to intellectual exchange between North and South (for instance, in collaborations between law schools at Warwick and Dar es Salaam) and to a robust reaction from African scholars, and political leaders such as Nkrumah in Ghana, to the strict legal formalism of doctrinal legal scholarship-recognising the need to contextualise law, that context being decolonisation.

The workshop provided opportunity for one-to-one sessions with editors, enabling authors to give a close reading and re-writing of draft articles. A central focus of discussion throughout the workshop was on how and where, as an early career researcher, one locates oneself as a scholar, whether that epistemic community is local, national, regional, continental or global. What it means to be a scholar of and from the Global South, in particular the continent of Africa-when it comes to appreciating one's work as having a global significance and generalisable insights, and for such global South scholarship to be externally recognised as a 'legitimate' site of knowledge production.

The workshop explored the complex issue of engagement by scholars in and from the global South with journals and publishers in the global North-and our responsibility as journal editors to engage with care and solidarity. This conversation took place against a backdrop of the need to challenge assumptions about knowledge production and what is deemed to be 'rigorous' or 'universal' knowledge 
and scholarship; and also in the context of a changing policy environment marked by an increasing prescriptiveness in higher education sectors across Africa-high expectations of $\mathrm{PhD}$ researchers and early career scholars with regard to publication, requirements to publish in 'recognised' journals, which had the effect of privileging knowledge produced or published outside the continent.

Whilst none of the participants in the Accra workshop were specifically working with feminist theory, I was rendered aware of our position of relative power as journal editors, and our responsibility to think about how to use the workshops we are involved into learn from and engage with critical anti-colonial work where it is being created. This may need more sustained engagement in the long run.

\section{NAIROBI: Dr. Zainab Naqvi}

'The missing reference is not necessarily Foucault or Habermas.' (Carli Coetzee 2018, 108)

In pre-colonial times Nairobi was known as 'Enkare Nairobi' to the local Maasai community which translates as 'the place of cold waters'. It rose to prominence for the Empire with the construction of the Kenya-Uganda railroad connecting the Indian Ocean coastline to the largest lake in Africa: Lake Victoria (or Lake Nyanza as it was known before colonisation). Given this position in colonial history, Nairobi was an apt location for a workshop focussed on socio-legal writing in the Global South held at the British Institute of East Africa under the direction of Freda Nkirote (BIEA Director) and supported by Teresia Ngandi. The workshop was convened by editors from Social and Legal Studies (Ambreena Manji, Cardiff); Strathmore Law Journal (John Osogo Ambani, Strathmore Law School - Nairobi); SA Crime Quarterly (Dee Smythe, University of Cape Town); American Journal of Legal History (Stefan Vogenauer, Max Planck); and Feminist Legal Studies (Zainab Naqvi, Coventry). The workshop was generously supported by the presence and participation of Smith Ouma (Strathmore Law School) along with Christina Moorhouse of the British Academy.

Around 15 early career scholars attended from Kenya, Nigeria, Ethiopia and South Africa and submitted a paper for feedback from an editor. Each editor was responsible for a small group of scholars and held group sessions discussing the meaning and nature of socio-legal, along with challenges of being an early career academic. Individual meetings were held to discuss participants' paper submissions and written feedback was provided along with a memory stick of helpful resources that were locked behind a paywall. Prior to attending the workshop, it did not even occur to me that there was a disparity in access to resources to this degree. It was frustrating to experience this realisation and humbling to see the high-quality submissions despite the ECRs not enjoying the same advantages that I do.

I read through the papers I had been assigned and provided written feedback before leaving for Nairobi. Upon reaching there and listening to Ambreena's introductory talk on the postcolonial condition of academia in the Global South, I was struck with a desire to change my comments whilst discussing my group members' 
papers with them. My main weakness was suggesting Global North scholarship to explore and include in their papers. My Global North perspective and knowledge was thrown starkly into relief by my ignorance of the work of path-breaking Africa-based academics like Professors Issa Shivji (1989), Yash P Ghai and Jill Cottrell Ghai (2013). The references in our work display our intellectual ancestry. They tell the reader who taught us and inspired us. Early career researchers in the Global South can show off their academic kin and ancestors using the bibliography as a decolonising technique - as a list of references that brings different partial knowledges together and exists unapologetically on its own terms (Coetzee 2018, 109-110; Fletcher 2015a, 245). Similarly, I went into the workshop with the mindset that I was supporting the participants with publication in the Global North, but this was not universally their aim. Some wanted to publish in local, regional or continental journals and discussions arose around the desire for a comprehensive list of journals being produced in Africa as an output from the workshop. ${ }^{1}$ The dissemination of the list is a decolonising technique in itself as it shares existing platforms for knowledge production in the Global South that are governed by Global South scholars and organisations.

Like the Accra workshop, there was less engagement with feminist perspectives by the participants which leads to a gap that we may be able to address but exploring the notion of 'socio-legal' and interdisciplinary work with the researchers ensured that feminist legal studies had a role to play. Lastly, I came away from the workshop with an understanding of the most important and least resource intensive decolonising technique of all: to read more scholarship from the Global South and introduce it into my own research and teaching. As a board we need to be more aware and invested in this to truly earn the label 'international journal' for FLS.

\section{RECIFE: Dr. Ruth Fletcher and Dr. Katie Cruz}

'Epistemic violence can be catalogued without much concern for the risk of reproducing colonial effects.' (Denise Ferreira da Silva 2015, 4)

The Recife workshop was held at the beautiful campus of Universidade Federal de Pernambuco (UFPE) in December 2018, a university in Northern Brazil which welcomed us into lush gardens and old colonial buildings adorned with anti-fascist banners. UFPE law colleagues Gustavo Ferreira Santos and João Paulo Allain, together with UFPE graduate and Social and Legal Studies editor, Henrique Carvalho (University of Warwick), hosted twelve researchers and another three journal editors at this writing workshop, the fourth and final one in the 2018 series. The Brazilian connection took the series to the continental home of the kind of critical

\footnotetext{
1 The working list has now been published on the Cardiff Law and Global Justice Centre website. See 'East Africa Law Journals List' available from: https://www.lawandglobaljustice.com/east-african-lawjournals-list.
} 
socio-legal research (Sieder et al. 2019), which has seen the emergence of Southern Criminology (Carrington et al. 2016, 2018) and of a dynamic group of academics and activists working at the boundaries of feminist legal studies (see further Lemaitre 2007, 2018). As a result, the heart of the workshop-the submitted papers-was made up of socio-legal research, which engaged directly, if not universally, with feminist concepts and methods, and enabled feminism to emerge as a strong touchstone of mutual curiosity and commitment. Máximo Sozzo (Universidad Nacional de Literol), an editor with Delito y Sociedad: Revista de Ciencias Sociales and Punishment and Society, and two editors from Feminist Legal Studies, ${ }^{2}$ Katie Cruz (University of Bristol) and Ruth Fletcher (QMUL), joined Carvalho as the workshop editors.

One of the interesting dynamics of the Recife workshop was watching the 'writing workshop' travel from the continent of Africa to that of South America, while picking up UK-based editors, and stopping off in Bangalore along the way. In anticipation of these travels, Manji and Harrington had organised a meeting at Cardiff in September 2018. Our reading of their and Coetzee's work had a chance to embed as we exchanged stories of attachments to this work. The mood of our preparation for Brazil was affected by the news that Jair Bolsonaro had been elected and was due to take up the role of President in January 2019. We had had that familiar academic conversation about whether we were doing the right thing in travelling to Brazil at this time. And we came to the equally familiar conclusion that it was better to travel, support and meet up with colleagues who were, directly or indirectly, cultivating alternative forms of life to those promoted by Bolsonaro. Carvalho had shared information about the ways in which humanities disciplines were being targeted by Bolsonaro, and we were also hearing about how academics were organising to respond. ${ }^{3}$ So when we walked onto the UFPE campus to find students and staff mingling under anti-fascist banners in beautiful buildings with painful colonial legacies, the atmosphere spoke to us of commitments to challenging the reproduction of colonial effects.

The workshop itself brought the journal editors and early-career researchers together to read works-in-progress and exchange over different practices of producing and publishing research. The programme opened with a multi-participant session led by contributions from Carvalho and Sozzo, moving through commentary from Cruz and Fletcher on critical editorial practice, and into discussion of publishing processes and expectations for the workshopping of the papers. Carvalho introduced the aims of the workshop and its intellectual debt to 'law in context' scholarship. He shared his experience as a Brazilian scholar who now works in the UK, and is on the editorial board of Social and Legal Studies. Sozzo spoke about his experience as an Argentinian criminologist who is a key contributor to 'Southern Criminology',

\footnotetext{
2 Another FLS editor, Dr. Sheelagh McGuinness (Bristol) participated in the process of developing the programme but was unable to travel to Recife in the end.

3 For one Brazilian account see here https://cjt.ufmg.br/en/2019/05/10/dismantling-of-education-theanti-intellectualist-policy-under-the-bolsonaro-government/ and for a letter from European academics see here https://www.theguardian.com/world/2018/nov/01/we-deplore-this-attack-on-freedom-of-expression -in-brazils-universities.
} 
and works between Australia and Argentina. The Southern Criminology school of thought describes itself as taking 'a journey to cognitive justice' by turning the origin stories of criminology on their head (Carrington et al. 2018). Scholars challenge the assumed global universality of criminology by challenging its long fascination with dangerous masculinities, itself based on an orientalist interpretation of men of colour from the Global South; and invest in methods and concepts that enhance the democratisation of knowledge.

We came away from his contribution with a new appreciation for the ways in which the context of South America with its multiple radical social justice movements had produced schools of critical criminologists. These scholars were not only engaged across research, teaching and activism in a way which spoke to a feminist mixing of roles; they were also engaged in speaking back to the universalising impulses of criminological scholarship of the Global North. As the discussion picked up themes from Sozzo's talk, one that continues to reverberate between the Recife meeting, the Cardiff meeting and beyond, is a critical commitment to 'counter-generalisation'. In Recife, we heard how Sozzo and colleagues were clearly engaged in producing scholarship which generalised from the particular, but in a way which was radical and transformative in centring the Global South as the source of theoretical frameworks appropriate to any global task of understanding everything from the disproportionate impacts of eco-crime to the colonial dynamics of gender violence. They refused to be particularised while speaking from the South and sidestepped the universalising impulse performed by so much criminological scholarship produced in and of the Global North, as it omits any reference to its Northernness. This resonated with our earlier discussions at Cardiff where we had reflected on editorial experience of working with scholars who under-represented the theoretical significance of their own work. The question of how we might collect and develop critical practices of counter-generalisation was live in our minds.

The second day was taken up with research conversations as editors met with authors to discuss each of the submitted papers on a one-to-one basis, and as groups of participants continued those conversations or started new ones. Pace and improvisation emerged as two techniques of 'intellectual kinship' (Coetzee 2018) which we cultivated collectively in seeking a workshop aesthetic that was attentive and relational. Participants commented afterwards that it was a relief to have an event with a slower pace, one which facilitated an intensity, or depth, of engagement but without the rush of the usual conference scene (see further van Marle 2018). Scheduling sessions in a way that allowed plenty of space for improvisation, so that we could take time to go over developments and connections, was important in addressing expectations about which literatures were appropriate. For us, the workshop in Recife illustrated the possibility of organising academic time in a way that thwarts our absorption into the publishing machine. By providing a path around that machine, the workshop allowed participants to step out together and think about the terms on which we step in again.

This point about 'taking time' is a refrain that is often heard at conferences and in university seminar rooms. Colleagues often comment that they learn as much in the conversational spaces that open up between sessions, that the driving force of a packed conference or seminar programme can be exhausting rather than stimulating. 
Even if we get an occasional thrill out of the intense commitment to making the academic show happen, too often there's a sense of giving ourselves up to the way that it is done. All of us have experience of academic organising in the 'internationalist' mode, which may present itself as critical and counter-cultural, but nonetheless relies on the processes of knowledge extraction, scholarly stardom and hyperproductivity that are mobilised by the re-colonising dynamics of contemporary academic capitalism (Coetzee 2018; see also Van Marle 2018; O’Donovan 2019). We left Recife with a sense of having taken back some time through the writing workshop and learned in a mood of 'modest engagement' (Harrington and Manji 2019). This was generative for us in enabling re-orientation as we consider different starting points for the counter-generalisations of critical socio-legal scholarship.

\section{On being decolonial and international: the FLS commitment}

Things need to change. Global South scholarship and scholars should have their rightful place at the kitchen table. Their feminism, legality and knowledge should form equal part of the mixture and it is our responsibility to work towards this. We need to nurture and publish more Global South scholars and research. We further need to ensure that the journal overall is equally representative: our aim for 'diversity of content' (Fletcher 2015b) should stretch to all content including editorials, reflections and book reviews. Through our work and role as editors, we need to build better networks with the Global South. We have started to address this by working further to develop our long-standing International Advisory Board and our participation in the writing workshops, but this is still in its infancy. Another priority is money: we need to carry on deploying wench tactics and argue for more open access options (Fletcher et al. 2017). The last time we tactically slowed down our labour, were kinder to ourselves and took time to produce the work we wanted. We have also been able to have a limited number of Global South connected articles made open access for a finite period to promote our attendance at the workshops.

We have started use our editorial visibility through open access spaces like these journal editorials to invite our readers in. In one editorial we explain our submission and review process in detail to explain away any mystery or mysticism in our workings (Fletcher 2015a). In this way, we want to encourage authors to submit their valuable work to us without fear of the unknown. In the writing workshops, there was a panel where each editor explained how submissions are processed and decisions are made to address this. Publishing in academia is important and scholars should feel confident that their hard work is being valued and ethically treated. Of course, we welcome your feedback as our fellow researchers and readers. If there are questions about the process, please ask us for clarification. If you want to discuss the suitability of your submission for FLS, we would be delighted to hear from you.

We are starting to explore the development of counter-generalisation as a mode of knowledge generation in our own editorial practice. Our current thinking suggests that counter-generalisation has four moves in its orchestration of the relationship between the particular and general on uneven epistemological terrain. One move that we sometimes see and could make more explicit in our own editorial 
writing, feedback to authors, and journal compilation, is 'side-stepping'. Side-stepping entails choreographing engagements with the (default) conceptual apparatuses and authors of the Global North in such a way that they appear to the side, rather than in the lead. Rather than opening a discussion of rights, state interventions and governance feminism by reference to, for example, Halley et al. (2018); we could cite first instead a lesser-known source, which draws fascinating insights about the interplay of rights, criminalisation and governance from Ecuador (Tapia 2018). Such choreography of sources interrupts the usual citation patterns by foregrounding the general explanatory power of a more marginal source, while acknowledging but relocating that of the less marginal. A second move that counter-generalisation might make as editorial practice is a reflexive shrinking or stretching of the particularisation of the knowledge produced in our journal, depending whether it is produced in the Global North or Global South. As editors we have found that it is more common for authors from the Global South to add the name of the country about which they write to the title of their paper. This is less likely when the author hails from a country of the Global North, particularly the UK or the US (although of course other rationales are also in play). One simple tactic would be to encourage reflection and a possible change in practice by suggesting the addition or dropping of the name of the country in the title, depending from where the work hails.

A third move is to engage more horizontalism in the use of different theoretical and explanatory frameworks from the Global South - the south to south move-so as to work against any assumptions that explanation has to go through the UK, or the Global North. One example in that regard is MacLeod et al's (2017) use of Verdeja's (2008) theory of reparative justice, developed in part through Latin American illustrations, in building reproductive justice as a theoretical framework applied to the evaluation of abortion law in South Africa and the UK. A fourth move is to encourage a writerly investment of generalising power in indigenous, local or everyday socio-legal terms. Mills' account of smadditizin' (2010) is an important example of how the process of subjectification in conditions of colonial racism is theorised through its Jamaican vernacular. If critical theory is performative and constitutive (Lloyd 2013) then FLS writers show us how to build theory every time they perform the theoretical contribution of language (see also Lugones 2010) as a carrier of a wealth of historical and geographical particularity.

In light of our experiences and our reflections, we intend to build further on the work that we have already been doing around Global South representation, open access and transparency. We have identified a need to investigate our practices and have decided that FLS needs to be placed on the kitchen table itself for further scrutiny. The ingredients that make up the journal need to be re-examined and adjusted to ensure that the feminism, legality and knowledge we are mixing is equally representative of the Global South. We intend to look further at our content from the inception of the journal to the present day, focussing on the level of Global South presence and participation. This will then be shared along with an explanation of the ways in which we can improve.

Finally, we continue to push for the scholars and scholarly practices of the Global South to have more space at the kitchen table. At two of the writing workshops, we noted that there was little explicit engagement with feminist legal studies. We intend 
to investigate how early career researchers in feminist legal studies are being supported with writing and publication in the Global South and think about how we can create more spaces for feminist legal studies in the writing workshops. To conclude this editorial, we shall briefly introduce the contents of this issue.

\section{This issue}

Emma Milne's article 'Concealment of Birth: time to repeal a 200-year old convenient stop gap?' critically discusses the criminal offence of concealment of birth (2019). The offence prohibits the secret disposal of the dead body of a child to conceal its birth in England and Wales. Milne argues that this rarely used offence is gendered because it is the birth mother who tends to be the defendant to this crime. It has been employed as a 'stop-gap' to punish women if homicide cannot be proven. The offence has wider implications for society by representing and perpetuating entrenched views of motherhood and appropriate maternal behaviour. In doing so, it leads to gendered moral judgement of women's behaviour leading to structural prejudice in the law. Through exploration of the historical context and analysis of several case transcripts from sentencing hearings for the offence, Milne demonstrates that even today, it is used in line with misogynistic expectations of women's behaviours around pregnancy and motherhood. For this reason, she argues that it should be repealed.

In 'Relational Vulnerability: The Legal Status of Cohabiting Carers' Ellen Gordon-Bouvier applies a lens of relational vulnerability to the status of cohabiting carers in English law (2019). She argues that the state's privatising and devaluing of care exposes carers to harm on economic, emotional and spatial levels. These harms cannot be explained away as the private choice of individuals who assume such responsibilities but must be viewed within the context of the state's behaviours. Whilst male domesticity is commercialised in the courts, female caregiving is characterised as altruistic thereby failing to attract adequate state support. Gordon-Bouvier argues that the state has an imperative to remedy the unsatisfactory conditions that it has created for cohabiting carers. Applying the lens of relational vulnerability, she argues that carers need to be made resilient by developing their relational networks. Without legal reform that acknowledges and addresses the state's role in generating caregiver vulnerability, genuine resilience cannot be achieved.

Moving back to criminal law, this time in the US state of Connecticut, Laura Vitis interrogates an offence implemented in 2010 that prohibited minors from engaging in sexting in 'Victims, Perpetrators and Paternalism: Image Driven Sexting Laws in Connecticut' (2019). The offence was intended to distinguish sexting from childabuse material but has instead resulted in the conflation of victims and perpetrators of image based sexual abuse thereby failing to achieve its aims. For example, in the Pennsylvanian case of Miller $v$ Skumanick, ${ }^{4}$ a prosecutor threatened to charge two teenage girls with child pornography offences after their semi-nude images

${ }^{4} 605$ F. Supp. 2d 634 (2009). 
were disseminated at school. Through analysis of the Bill drafting process, media reports and case law, Vitis critically examines the implications of the offence to argue that the current legal approach is paternalistic and is being used to register and shape anxieties about young people's sexual and technological activities. The offence reproduces problematic discourses around victim-blaming and paternalism that require attention.

In addition to these three articles, Alina Tryfonidou's commentary on the ECJ ruling in the Coman $^{5}$ case analyses the decision to include same-sex spouses of EU citizens within the definition of 'spouse' for the purposes of free movement of persons (2019). Whilst the judgment is a much-welcomed first step towards marriage equality at a cross-border level, there are still gaps in protection for same-sex couples in EU law. For example, the ruling applies purely to cross-border situations and cannot support couples when the case is purely internal to a member state. Tryfonidou concludes that it is unlikely political action will be taken to fill the gaps and resolve the remaining issues but hopes that the ECJ will have the chance to do so in the future.

This issue concludes with three book reviews each engaging with very different areas of feminist inquiry. Doris Buss (2019) reviews Sara Meger's Rape Loot Pillage: The Political Economy of Sexual Violence in Armed Conflict; Ania Zbyszewska (2019) reviews Gender Equality in Law: Uncovering the Legacies of Czech State Socialism by Barbara Havelkova, and Neil Cobb (2019) shares his thoughts on Lucy Finchett-Maddock's Protest, Property and the Commons: Performances of Law and Resistance.

\section{References}

Aidoo, Ama Ata. 1977. Our sister killjoy: Or, reflections from a black-eyed squint. London: Longman.

Briggs, Ryan, and Scott Weathers. 2016. Gender and location in african politics scholarship: The other white man's burden? African Affairs 115(460): 466-489.

Buss, Doris. 2019. Rape loot pillage: The political economy of sexual violence in armed conflict. Feminist Legal Studies. https://doi.org/10.1007/s10691-018-9362-7.

Carrington, Kerry, Russell Hogg, and Máximo Sozzo. 2016. Southern criminology. British Journal of Criminology 56(1): 1-20. https://doi.org/10.1093/bjc/azv083.

Carrington, Kerry, Russell Hogg, John Scott, Máximo Sozzo, and Reece Walters. 2018. Southern criminology. London: Routledge.

Cobb, Neil. 2019. Protest, property and the commons: Performances of law and resistance. Feminist Legal Studies. https://doi.org/10.1007/s10691-019-09398-y.

Coetzee, Carli. 2018. Unsettling the air-conditioned room: Journal work as ethical labour. Journal of the African Literature Association 12(2): 101-115.

da Silva, Denise Ferreira. 2015. Reading Art as Confrontation. E-Flux Journal 56th Venice Biennale, August 13th. Available here http://supercommunity.e-flux.com/texts/reading-art-as-confrontation/. Accessed 27 July 2019.

Fletcher, Ruth. 2015a. Responding to submissions and introducing issue 23 (1). Feminist Legal Studies 23(1): 1-6.

\footnotetext{
5 Coman, Hamilton and Asociatia Accept v Inspectoratul General pentru Imigrări and Ministerul Afacerilor Interne (C-673/16) EU:C:2018:385.
} 
Fletcher, Ruth. 2015b. FLaK: Mixing feminism, legality and knowledge. Feminist Legal Studies 23(3): 241-252.

Fletcher, Ruth, Julie McCandless, Yvette Russell, and Dania Thomas. 2016. Internationalism and commitment at the kitchen table. Feminist Legal Studies 24(1): 1-6.

Fletcher, Ruth, Diamond Ashiagbor, Nicola Barker, Katie Cruz, Nadine El-Enany, Nikki Godden-Rasul, Emily Grabham, Sarah Keenan, Ambreena Manji, Julie McCandless, Sheelagh McGuinness, Sara Ramshaw, Yvette Russell, Harriet Samuels, Ann Stewart, and Dania Thomas. 2017. Wench tactics? Openings in conditions of closure. Feminist Legal Studies 25(1): 1-23.

Ghai, Yash Pal, and Jill Cottrell Ghai (eds.). 2013. Ethnicity, nationhood and pluralism: Kenyan perspectives. Nairobi: Katiba Institute.

Gordon-Bouvier, Ellen. 2019. Relational vulnerability: The legal status of cohabiting carers. Feminist Legal Studies. https://doi.org/10.1007/s10691-019-09404-3.

Halley, Janet, Prabha Kotiswaran, Rachel Rebouché and Hila Shamir. 2018. Governance feminism: An introduction. Minnesota University Press.

Harrington, John, and Ambreena Manji. 2017a. The limits of socio-legal radicalism: Socio-legal studies and third world scholarship. Social and Legal Studies 26(6): 700-715.

Harrington, John and Ambreena Manji. 2017b. Legal Education and the End of Empire: Renewing Cosmopolitan Kinship. UCD Working Papers in Law, Criminology \& Socio-Legal Studies Research Paper. 17/17. https://ssrn.com/abstract=3065996 or http://dx.doi.org/10.2139/ssrn.3065996.

Harrington, John, and Ambreena Manji. 2019. Socio-legal studies, the global south and knowledge production: Reflections on a series of writing workshops. Socio-Legal Newsletter of the SLSA 87: $10-11$.

Kotiswaran, Prabha. 2015. Valverde's chronotopes of law: Reflections on an agenda for socio-legal studies. Feminist Legal Studies 23(3): 353-359.

Lebeloane, Lazarus Donald Mokula "Oupa". 2017. Decolonizing the Social Curriculum for Equity and Social Justice in South Africa. KOERS Bulletin for Christian Scholarship 82(3): 1-10.

Lemaitre, Julieta. 2007. Legal fetishism at home and abroad. Unbound 3(6): 6-18.

Lemaitre, Julieta. 2018. The view from somewhere: On samuel Moyn's not enough. Law and Political Economy 9 July https://lpeblog.org/2018/07/09/the-view-from-somewhere-on-samuel-moyns-notenough/Accessed 12 July 2019.

Lloyd, David. 2013. What's in a Name: The Dialectics of Diaspora and Irish Emigration Breac: A Digital Journal of Irish Studies https://breac.nd.edu/articles/whats-in-a-name-the-dialectics-of-diasporaand-irish-emigration/. Accessed 1 July 2019.

Lugones, Maria. 2010. Towards a Decolonial Feminism. Hypatia 25(4): 742-759.

MacLeod, Catriona, Sian Beynon-Jones, and Merran Toerien. 2017. Articulating reproductive justice through reparative justice Culture. Health and Sexuality 19(5): 601-615.

Manji, Ambreena, and Peter Mandler. 2019. Parliamentary scrutiny of aid funding: The case of the global challenges research fund. Parliamentary Affairs 72(2): 353-378.

Medie, Peace, and Alice Kang. 2018. Power, knowledge and the politics of gender in the global south. European Journal of Politics and Gender 1(1-2): 37-54.

Mills, Charles. 2010. Smadditizin'. In Radical theory, caribbean reality: Race, class and social domination. Kingston: University of the West Indies Press.

Milne, Emma. 2019. Concealment of Birth: time to repeal a 200-year old convenient stop gap? Feminist Legal Studies. https://doi.org/10.1007/s10691-019-09401-6.

Mohanty, Chandra Talpade. 1984. Under western eyes: Feminist scholarship and colonial discourses. Boundary 2 12(3): 333-358.

Mohanty, Chandra. 2002. "Under western eyes" revisited: Feminist solidarity through anticapitalist struggles. Signs: Journal of Women and Culture in Society 28(2): 499-535.

O'Donovan, Orla. 2019. What is to be done about the enclosures of the academic publishing oligopoly? Community Development Journal 54(3): 363-370.

Shivji, Issa. 1989. The concept of human rights in Africa. Senegal: CODESRIA.

Sieder, Rachel, Karina Ansolabehere, and Tatiana A.Alfonso Sierra. 2019. Routledge handbook of law and society in Latin America. London: Routledge.

Tapia, Silvana. 2018. Feminism and penal expansion: The role of rights-based criminal law in post neoliberal ecuador. Feminist Legal Studies 26(3): 285-306.

Tryfonidou, Alina. 2019. The EU Top Court Rules that Married Same-Sex Couples Can Move Freely Between EU Member States as "Spouses": Case C-673/16, Relu Adrian Coman, Robert Clabourn 
Hamilton, Asociaţia Accept v Inspectoratul General pentru Imigrări, Ministerul Afacerilor Interne. Feminist Legal Studies. https://doi.org/10.1007/s10691-019-09397-z.

Valverde, Mariana. 2015. On chronotopes of law. Feminist Legal Studies 23(3): 349-352.

Van Marle, Karin. 2018. Life is not simply fact: Aesthetics, Atmosphere and the Neo-liberal University. Law and Critique 29: 293-310.

Verdeja, Ernesto. 2008. A critical theory of reparative justice. Constellations 15(2): 208-222.

Vitis, Laura. 2019. Victims, perpetrators and paternalism: image driven sexting laws in connecticut. Feminist Legal Studies. https://doi.org/10.1007/s10691-019-09407-0.

wa Thiong'o, Ngũgĩ. 1986. Decolonising the mind: The Politics of Language in African Literature. London: James Currey.

Xaba, Wanelisa. 2018. The decolonization manifesto. In Decolonization and feminisms in global teaching and learning, ed. Sara Jong, Rosalba Icaza, and Olivia Rutazibwa, 69-74. London: Routledge.

Zbyszewska, Ania. 2019. Gender equality in law: Uncovering the legacies of czech state socialism. Feminist Legal Studies 1: 2. https://doi.org/10.1007/s10691-018-9379-y.

Publisher's Note Springer Nature remains neutral with regard to jurisdictional claims in published maps and institutional affiliations. 